\title{
PENGEMBANGAN SUMBER DAYA MANUSIA (SDM) MELALUI PENINGKATAN MUTU PENDIDIKAN, EKONOMI, DAN KESEHATAN BERBASIS TEKNOLOGI DAN HUKUM DI DESA BARENGKOK
}

\author{
Muhammad Fahri ${ }^{1}$, M. Iqbal Pahlevi, Lisyanti Istithoah, Nur Samsiah ${ }^{2}$ \\ fahri@fai.uika-bogor.ac.id \\ Dosen Fakultas Agama Islam ${ }^{1}$, Mahasiswa KKN Kelompok 51 Tahun $2018^{2}$
}

\begin{abstract}
ABSTRAK
Penulisan laporan ini bertujuan untuk memaparkan hasil dari kegiatan Kuliah Kerja Nyata kami selama 30 hari ini. Setelah mengadakan pengamatan langsung di Desa Barengkok, Kecamatan Leuwiliang Kabupaten Bogor sebenarnya tidak banyak permasalahan yang dialami oleh warganya. Berdasarkan data yang diperoleh, desa barengkok terbagi dalam 12 RW yang dari masing-masing RW tersebut terdapat 5 RT. Penduduk desa barengkok mayoritas berprofesi sebagai buruh tani, petani, dan wiraswasta. Namun ada juga beberapa yang berprofesi sebagai Pegawai Negeri Sipil (PNS). Sebagian besar warga desa barengkok beragama Islam, hal itu terbukti dari adanya beberapa pondok pesantren yang cukup terkenal. Maka dari itu kami kelompok 51 KKN Tematik Terintegrasi Universitas Ibn Khaldun Bogor selalu menyelipkan kegiatan keagamaan dalam setiap program kerja yang kami buat. Kami membagi program kerja kami ke dalam beberapa bidang yakni pendidikan, ekonomi, hukum, kesehatan, serta keagamaan yang berpedoman pada masing-masing fakultas. Adapun bentuk dari program kerja kami ini terdapat beberapa macam diantaranya penyuluhan, terjun langsung pada setiap kegiatan masyarakat, mengadakan tabligh akbar, juga menanam seribu pohon guna melestarikan lingkungan sekitar desa barengkok. Dilihat dari program-program tersebut maka mahasiswa berperan sebagai fasilitator, dinamisator dan motivator.
\end{abstract}

\section{Kata kunci: KKN Tematik, mayoritas profesi, program kerja.}

\section{PENDAHULUAN}

Kuliah Kerja Nyata (KKN) adalah bentuk kegiatan pengabdian kepada masyarakat oleh mahasiswa dengan pendekatan lintas keilmuan dan sektoral pada waktu dan daerah tertentu. Pelaksanaan kegiatan KKN biasanya berlangsung antara satu sampai dua bulan dan bertempat di daerah setingkat desa. Direktorat Jenderal Pendidikan Tinggi di Indonesia telah mewajibkan setiap perguruan tinggi untuk melaksanakan KKN sebagai kegiatan intrakurikuler yang memadukan tri dharma perguruan tinggi yaitu: pendidikan, penelitian, dan pengabdian kepada masyarakat.

Pada dasarnya Kuliah Kerja Nyata (KKN) merupakan bentuk pengabdian nyata seorang mahasiswa kepada masyarakat yang sebenarnya. Setelah mendapatkan materi perkuliahan yang senantiasanya dapat berguna di dalam lingkungan masyarakat itu sendiri.

Dalam kegiatan pengabdiannya pada masyarakat, mahasiswa memberikan pengalaman ilmu pengetahuan, teknologi, seni, dan agama untuk memberikan 
pengarahan agar dapat memecahkan masalah dan menanggulanginya secara tepat. Selain itu, pembenahan sarana dan prasarana merupakan kegiatan yang dilakukan serta menjadi program kerja bagi mahasiswa. Dengan kata lain, melalui KKN ini, mahasiswa membantu pembangunan dalam masyarakat.

Dalam meningkatkan kualitas kehidupan masyarakat kinerja yang harus diupayakan secara berkesinambungan, yaitu dengan menerapkan berbagai model dan corak pembangunan. Oleh karena itu, baik secara kelompok maupun individual, dalam KKN ini sudah pasti mahasiswa mengamati dengan cermat apa yang menjadi permasalahan dan petensi yang dimiliki masyarakat dengan melakukan penelitian pada setiap sektor kehidupan bermasyarakat.

\section{Gambaran Umum Lokasi Sasaran}

Luas Desa/Kelurahan : 450 Hektar Batas Wilayah

- Sebelah Utara : Desa Leuwimekar

- Sebelah Timur : : Desa Situ Ilir

- Sebelah Selatan : Desa Karacak

- Sebelah Barat : Desa Cibeber Ii

\section{Kondisi Geografis}

Ketinggian Tanah

Curah Hujan : $600 \mathrm{Dpl}$

Topografi : $200 \mathrm{Mm} / \mathrm{Thn}$

Suhu Udara Rata-Rata: $32^{\circ} \mathrm{c}$

\section{Peruntukkan Lahan}

$\begin{array}{ll}\text { Jalan } & : 8 \mathrm{~km} \\ \text { Sawah dan ladang } & : 380 \text { hektar } \\ \text { Empang/kolam } & : 2 \text { hektar } \\ \text { Pemukiman \& perumahan: } 61 \text { hektar } \\ \text { Pemakaman/TPU } & : 0,5 \text { hektar } \\ \text { Lain-lain } & : 3 \text { hektar }\end{array}$

\section{Kependudukan}

Jumlah penduduk menurut jenis kelamin

- Laki-Laki : 6.684 jiwa

- Perempuan : 5.979 jiwa

Jumlah penduduk menurut tingkat pendidikan

$\begin{array}{ll}\text { TK/TPA/PAUD } & : 120 \text { jiwa } \\ \text { SD } & : 674 \text { jiwa } \\ \text { SMP } & : 2.639 \text { jiwa } \\ \text { SMA/MA/PAKET C } & : 3.918 \text { jiwa } \\ \text { D1-D3 } & : 169 \text { jiwa } \\ \text { S1 } & : 102 \text { jiwa } \\ \text { S2 } & : 7 \text { jiwa }\end{array}$

Jumlah penduduk menurut mata pencaharian

$\begin{array}{ll}\text { - PNS } & : 102 \text { jiwa } \\ \text { - PNS POLRI } & : 2 \text { jiwa } \\ \text { - PNS TNI } & : 12 \text { jiwa } \\ \text { - Pensiunan PNS } & : 45 \text { jiwa } \\ \text { - Karyawan Swasta } & : 315 \text { jiwa } \\ \text { - Wiraswasta } & : 546 \text { jiwa } \\ \text { - Pedagang } & : 135 \text { jiwa } \\ \text { - Petani } & : 425 \text { jiwa } \\ \text { - Buruh Tani } & : 1.222 \text { jiwa } \\ \text { - Jasa } & : 12 \text { jiwa }\end{array}$

Jumlah aparatur pemerintah desa

$\begin{array}{ll}\text { Kepala desa } & : 1 \text { orang } \\ \text { Sekretaris desa } & : 1 \text { orang } \\ \text { Kepala urusan } & : 4 \text { orang } \\ \text { Kepala dusun } & : 5 \text { orang } \\ \text { Bendahara desa } & : 1 \text { orang } \\ \text { Anggota BPD } & : 11 \text { orang }\end{array}$

\section{Lembaga kemasyarakatan Desa}

- Ketua RW : 12 orang

- Ketua RT : :61 orang

- TP. PKK : : 7 orang

- Pengurus LPM Desa: 9 orang

- Pengurus Karang Taruna: 17 orang 
Sarana dan Prasarana

$\begin{array}{ll}\text { Kantor desa } & : 1 \text { buah } \\ \text { Pos kesehatan } & : 1 \text { buah } \\ \text { Poskamdes } & : 1 \text { buah } \\ \text { Posyandu } & : 12 \text { buah } \\ \text { Pos ronda/kamling } & : 12 \text { buah }\end{array}$

Sarana dan Prasarana Pendidikan

PAUD : 5 unit

SD/MI : 3 unit

SMP/MTS : 2 unit

SMA/Madrasah Aliyah: 2 unit

Pondok Pesantren : 2 unit

Majlis Ta'lim : :36 unit

Sarana dan prasarana peribadatan

$\begin{array}{ll}\text { Masjid } & : 10 \text { unit } \\ \text { Mushola } & : 25 \text { unit }\end{array}$

\section{Kondisi Masyarakat}

Desa Barengkok termasuk wilayah dari kecamatan Leuwiliang yang memiliki luas wilayah 450 hektar. Kepadatan penduduk sudah mencapai 12.663 jiwa. Letak geografis desa barengkok berada di wilayah kabupaten bogor.

Keseharian masyarakat desa barengkok ini beragam, dari mulai buruh tani, pedagang, wiraswasta hingga Pegawai Negeri Sipil (PNS).

Sebagian besar jalan lingkungan barengkok sudah diperbaiki,meskipun ada beberapa gang yang belum tersentuh oleh rabat beton. Kondisi air sebenarnya baikbaik saja, hanya saja saat kami datang kondisinya memang sedikit kekeringan. Namun itupun tidak menghambat aktifitas kami dan memang pemerintah desa sedang dalam pembangunan irigasi. 


\section{METODE PENGABDIAN}

Tahapan pelaksanaan untuk kegiatan ini sebagaimana terlihat pada bagan sebagai berikut:

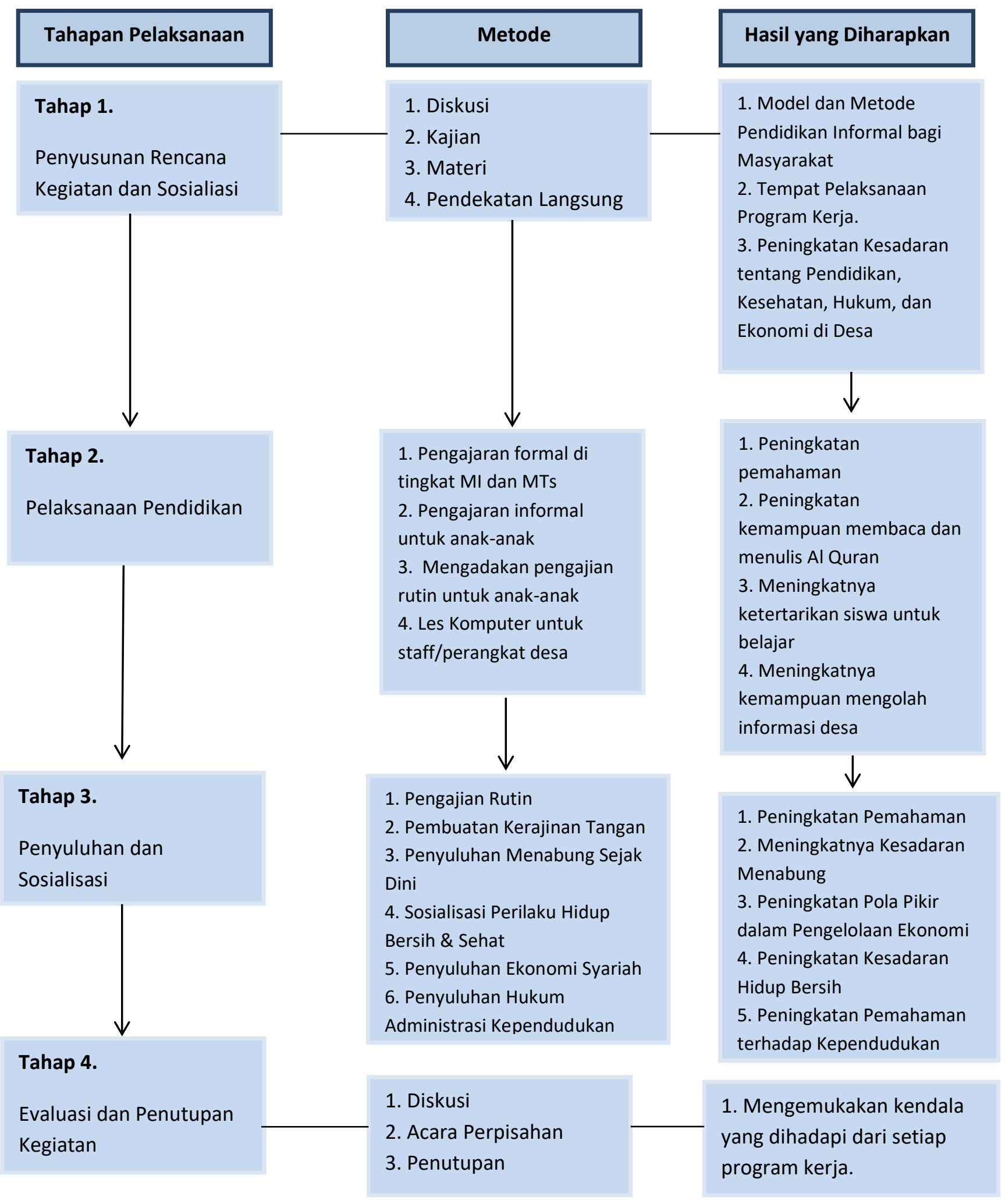


JADWAL KEGIATAN

\begin{tabular}{|c|c|c|c|c|c|}
\hline \multirow{2}{*}{ NO } & \multirow{2}{*}{ Kegiatan } & \multicolumn{4}{|c|}{ Minggu } \\
\hline & & 1 & 2 & 3 & 4 \\
\hline 1 & Penyusunan Rencana Kegiatan & & & & \\
\hline 2 & Sosialisasi Rencana Kegiatan & & & & \\
\hline 3 & Pengajian Pemuda & & & & \\
\hline 4 & $\begin{array}{l}\text { Pengajaran Formal di Sekolah MI Mathlaul Anwar } \\
\text { dan MTs Nurul Iman }\end{array}$ & & & & \\
\hline 5 & Pengajaran Informal untuk anak-anak di Posko & & & & \\
\hline 6 & $\begin{array}{l}\text { Penjurian untuk Karnaval 17an tingkat Kecamatan } \\
\text { Leuwiliang }\end{array}$ & & & & \\
\hline 7 & $\begin{array}{l}\text { Keikutsertaan menjadi panitia Tabligh Akbar di Kp. } \\
\text { Geledug RW } 03\end{array}$ & & & & \\
\hline 8 & $\begin{array}{l}\text { Pembuatan Celengan Handmade di Pengajaran } \\
\text { Informal }\end{array}$ & & & & \\
\hline 9 & Senam Sehat di MI Mathlaul Anwar & & & & \\
\hline 10 & $\begin{array}{l}\text { Pelatihan Sorting Data untuk staff/perangkat desa di } \\
\text { Kantor Desa Barengkok }\end{array}$ & & & & \\
\hline 11 & $\begin{array}{l}\text { Keikutsertaan dalam Program Posyandu Keliling di } \\
\text { RW } 03\end{array}$ & & & & \\
\hline 12 & Nonton Bareng Film Edukasi di Pengajaran Informal & & & & \\
\hline 13 & Penyuluhan Hukum Administrasi Kependidikan & & & & \\
\hline 14 & Penyuluhan Perilaku Hidup Bersih dan Sehat & & & & \\
\hline 15 & $\begin{array}{l}\text { Penyuluhan Ekonomi; Pengelolaan Keuangan } \\
\text { Berbasis Syariah untuk BUMDES }\end{array}$ & & & & \\
\hline 16 & Pengajian dengan BKMT & & & & \\
\hline 17 & Piknik Anggota Kelompok & & & & \\
\hline 18 & Penyerahan 1000 Bibit Pohon untuk Desa Barengkok & & & & \\
\hline
\end{tabular}

\section{Metode Pendekatan}

Dalam hal ini, mengidentifikasi masalah adalah hal yang paling mendasar yang harus kami lakukan, sehingga kami dapat lebih fokus dan terarah dalam melaksanakan program kerja. Adapun program kerja kami tersusun melalui beberapa tahap, yaitu:

\section{Tahap Observasi dan Konsolidasi}

Pada tahap pertama ini kami melakukan pendataan di Balai Desa dengan mewawancarai Aparat Desa
Barengkok mengenai kondisi lingkungan, keadaan masyarakat, kegiatan masyarakat, sarana dan prasarana yang ada, yang meliputi pendidikan, peribadatan, kesehatan, olahraga dan lain-lain. Kemudian kami melakukan silaturahmi kepada ketua RT, ketua RW, tokoh masyarakat, alim ulama, guru, dan tokoh pemuda, untuk melakukan wawancara. Hal ini dimaksudkan untuk mendapatkan gambaran umum dan menggali masalah yang dihadapi oleh masyarakat. Dari silaturahmi ini kami mendapatkan manfaat 
ganda yaitu disamping untuk menjalin keakraban dan kekeluargaan, juga untuk keperluan pencarian informasi serta eksplorasi permasalahan.

\section{Tahap Klasifikasi dan Analisis}

Pada tahap ini kami memilih masalahmasalah yang ada menjadi tiga kategori, yaitu: masalah yang sensitif (berat), masalah yang sedang, dan masalah yang ringan.Kemudian kami mengalisis dengan kemampuan yang ada mengenai penentuan prioritas masalah yang sekiranya dapat menjadi program kerja kami.

\section{Tahap Sosialisasi dan Konfirmasi}

Setelah mengklasifikasi dan mengalisis masalah, kami menyusun program kerja sementara. Setelah itu kami melaporkan kepada pihak desa mengenai program kerja sementara yang sudah tersususun.

\section{Partisipasi Masyarakat dalam Pelaksanaan Program}

Partsipasi masyarakat yang dapat dilakukan dalam kegiatan ini adalah:

1. Mempersiapkan masyarakar dari anakanak untuk bersedia mengikuti program pendidikan.

2. Mempersiapkan tempat untuk melaksanakan pendidikan kepada Kepala Sekolah MI Mathlaul Anwar dan MTs Nurul Iman.

3. Pelaksanaan kegiatan pembinaan untuk pendidikan informal yaitu les, pengajian, dan pembuatan prakarya.

4. Melakukan Monitoring pelaksanaan kegiatan untuk masyarakat.

\section{Langkah Evaluasi}

Evaluasi yang dilakukan adalah dengan tahapan-tahapan berikut:

1. Evaluasi Proses, yang terkait dengan perencanaan, pelaksanaan, dan monitoring kegiatan.

2. Evaluasi Hasil, yang dilakukan setelah suatu program selesai dilaksanakan.

3. Evaluasi Dampak, yang dilakukan setelah seluruh program selesai dilaksanakan sampai penutupan.

\section{REALISASI PROGRAM}

\section{Program Bidang Pendidikan}

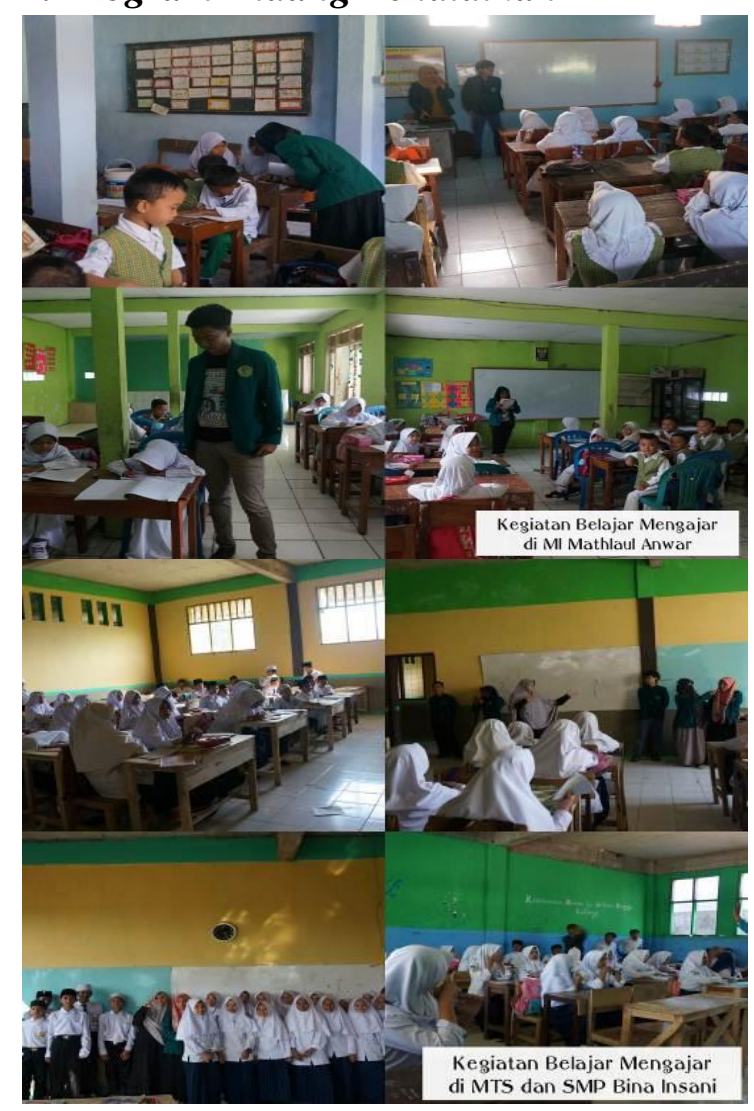

\section{a. Pengajaran Formal}

Program ini dilaksanakan di dua tempat. Yaitu MI Mathlaul Anwar di jenjang kelas 2, 3, dan 5 dan MTs Nurul Iman di jenjang kelas 8. Pengajaran ini mengimplementasikan cara mengajar dan metode yang menarik untuk siswa dan sedikit berbeda dengan metode yang biasanya guru gunakan. 


\section{b. Pengajaran Informal}

\section{(Bimbel)}

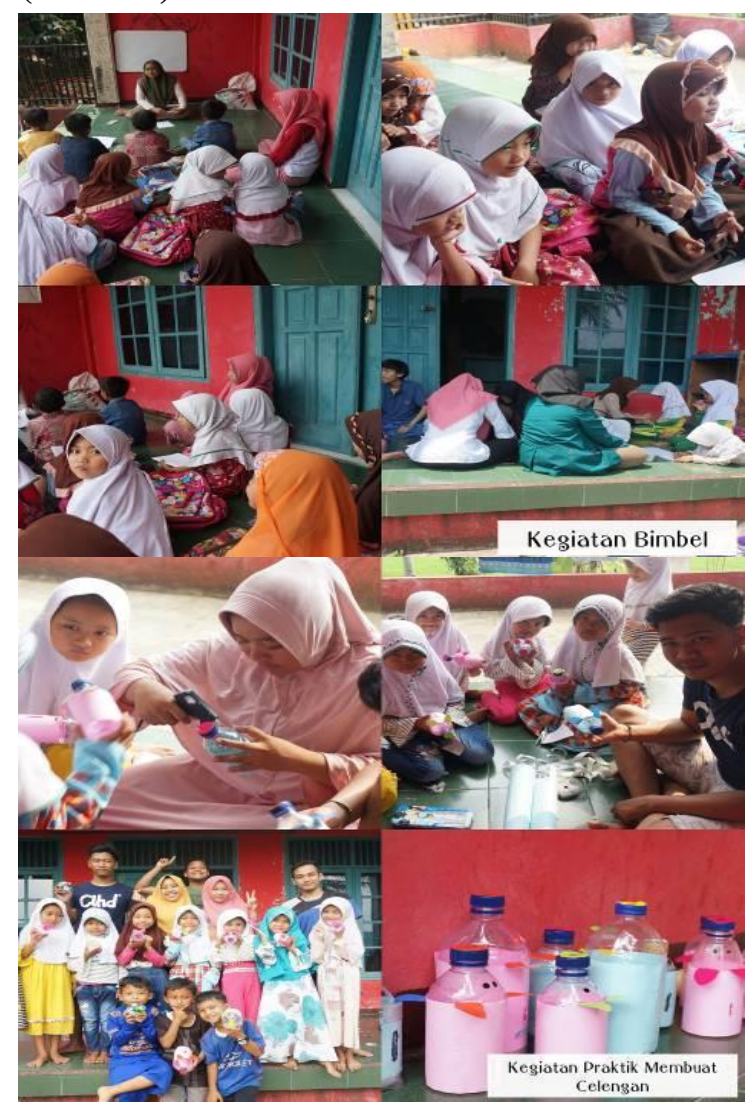

Bimbel ini dilaksanakan agar anak-anak bisa mendapatkan pembelajaran yang lebih menyenangkan dan tidak formal seperti halnya yang mereka dapatkan di sekolah. Dalam bimbel ini akan disesuaikan setiap harinya apakah anakanak akan belajar pelajaran umum atau mengaji. Selain itu, anak-anak belajar membuat prakarya celengan sekaligus penyuluhan tentang menabung sejak dini di minggu kedua. b. Senam Sehat

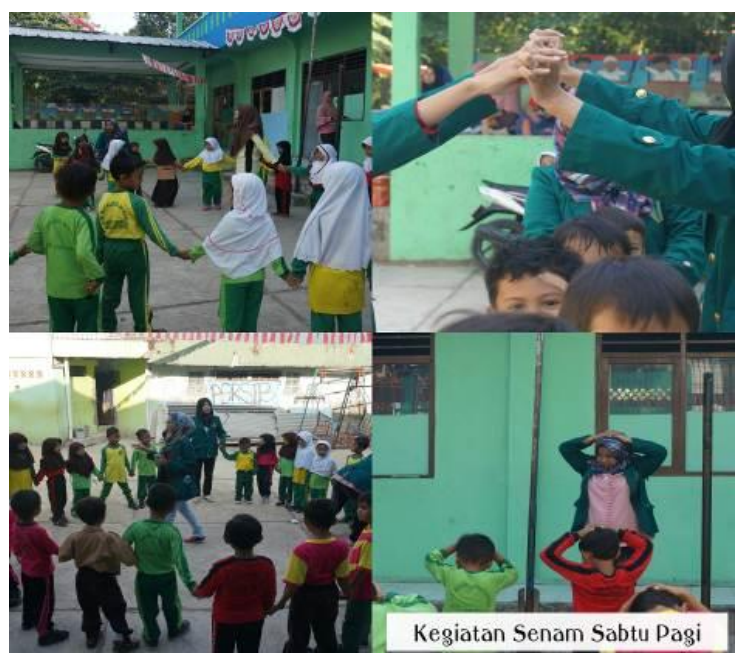

d. Penayangan Film Edukasi

Penayangan film edukasi ini dilaksanakn di minggu ketiga. Tepatnya di hari Rabu dan Kamis berlokasi di Posko.

\section{e. Pengajaran Kebahasaan}

Program ini dilaksanakan di Ponpes Nurul Iman setiap malam Sabtu pukul 21.00. Materi kebahasaan ini merupakan salah satu pembelajaran utama di Pondok Pesantren Salafi Modern ini.

\section{Program Bidang Ekonomi}

\section{a. Penyuluhan Pengelolaan Keuangan} berbasis Syariah untuk BUMDES

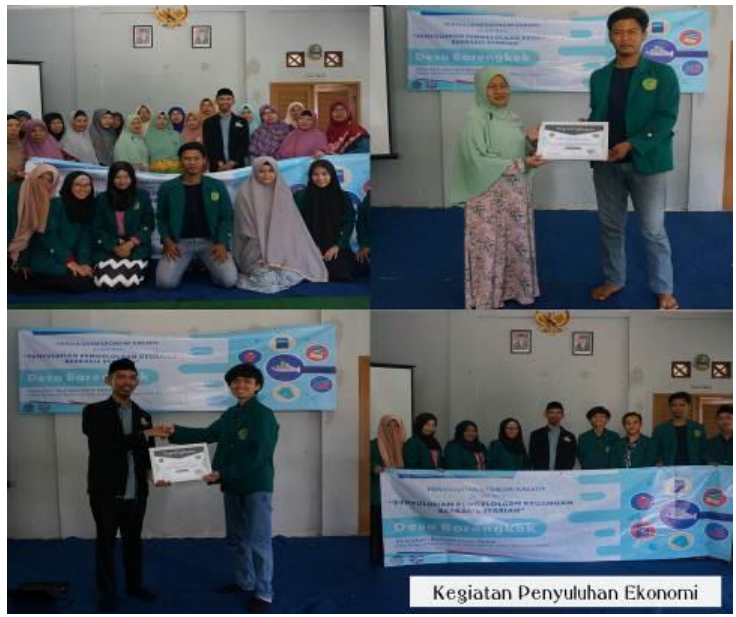

Penyuluhan ini dilaksanakan di minggu keempat, dengan sasarannya kalangan ibu-ibu di Desa Barengkok. Narasumber yang mengisi materi ini adalah Bastaka 
Ilham Akbar, seorang penggiat ekonomi syariah. Adapun penyuluhan ini ditujukan agar ibu-ibu bisa lebih memahami bagaimana mengelola keuangan yang berbasis, sekaligus agar pemahamannya bisa diimplementasikan untuk BUMDES yang kebetulan akan dibentuk pada bulan November tahun ini.

\section{Program Bidang Kesehatan}

\section{a. Penyuluhan Perilaku Hidup Bersih} dan Sehat

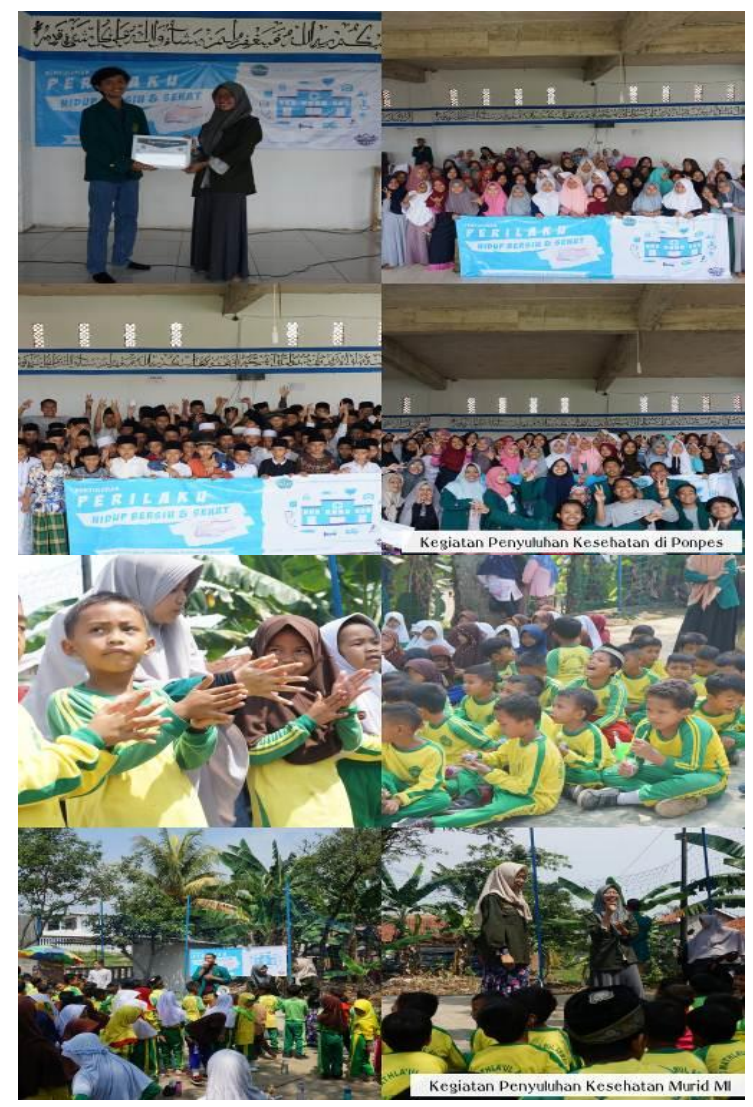

Penyuluhan ini dilaksanakan di dua tempat. Yaitu MI Mathlaul Anwar dan Ponpes Nurul Iman khususnya di tingkat santri dan santriwati MTs.

\section{Program Bidang Hukum}

\section{a. Penyuluhan Hukum Administrasi} Kependudukan

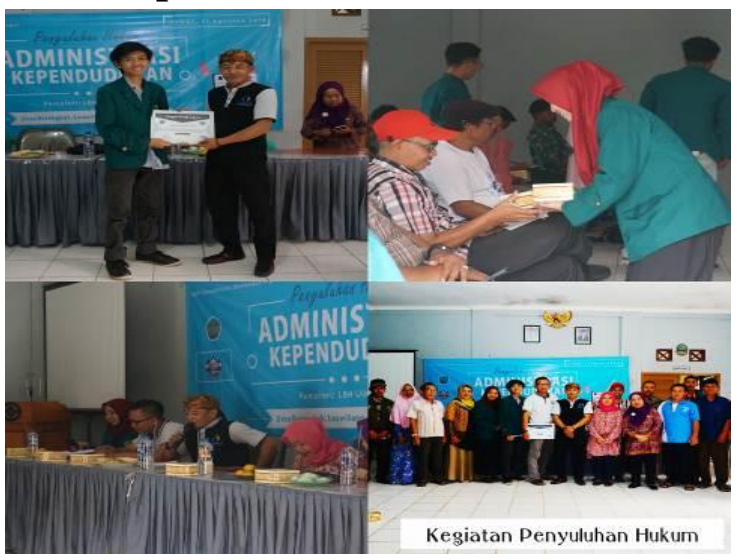

Penyuluhan ini mengambil sasaran bapak-bapak dan perangkat desa Barengkok, yang diwakili oleh seluruh ketua RT maupun RW yang ada di desa tersebut. Narasumber yang menjadi pembicara dalam acara ini adalah Bapak Ewil Hidayat S.Ap, yang merupakan salah satu staff kependudukan di Kantor Kecamatan Leuwiliang. Banyak yang dibahas dalam acara ini, terutama tentang pengurusan KTP, KK, hingga hal-hal yang perlu diurus jika ada kepindahan kependudukan.

\section{Program Bidang Lingkungan}

\section{a. Pemberian 1000 Bibit Pohon untuk} Desa Barengkok

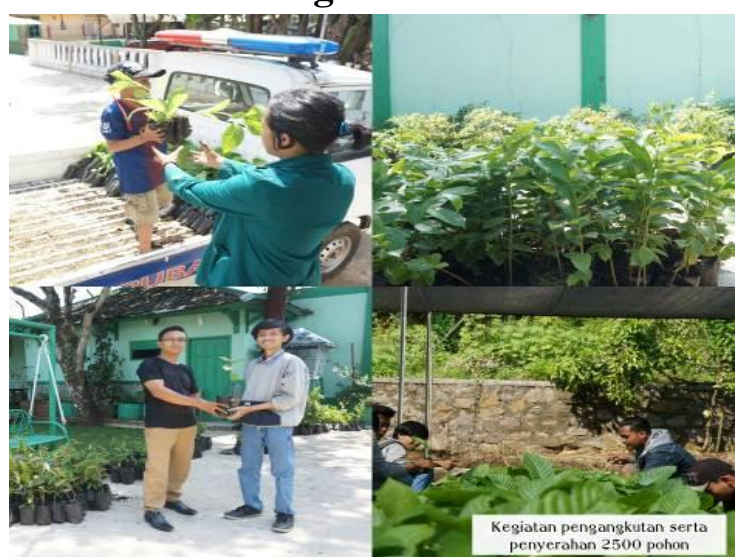

Kegiatan ini dilaksanakan di minggu keempat. Bibit yang kami dapatkan merupakan hasil pengajuan dari Institut Pertanian Bogor (IPB). Bibit-bibit ini 
merupakan salah satu program Kementerian yang sudah dicanangkan dari 5 tahun lalu dan ditujukan untuk siapa saja yang membutuhkan. Kami mengajukan surat-surat dan titik lokasi yang akan dilakukan penanaman sehingga pengajuan tersebut dapat diterima oleh pihak IPB. Bibit-bibit pohon yang diberikan ke desa antara lain pohon jabon, segon, salam, sirsak, durian, manggis, dan sayur kelewuh. Pembagian bibit pohon tersebut dilakukan oleh Sekretaris Desa Barengkok dan disalurkan kepada setiap ketua RW yang ada di desa ini.

\section{KESIMPULAN}

Desa Barengkok merupakan salah satu desa yang berada di kecamatan Tenjolaya kabupaten Bogor. Desa yang dipimpin oleh bapak Abdul Tawakal , menjadi lokasi dilaksanakannya Kuliah Kerja Nyata kelompok 51 pada tanggal 07 agustus sampai 05 september 2018 oleh mahasiswa Universitas Ibn Khaldun Bogor yang terdiri dari Fakultas Ekonomi, Fakultas Keguruan dan Ilmu Pendidikan, Fakultas Agama Islam, Fakultas Hukum, Fakultas Kesehatan dan Fakultas Teknik. Adapun lokasi tepatnya program kegiatan KKN bertempat di RT 02 RW 03, Desa Barengkok, Kecamatan Leuwiliang, Kabupaten Bogor.

Program-program kerja yang telah dilaksanakan terdiri dari beberapa bidang yakni bidang pendidikan, ekonomi, keagamaan, kesehatan, bidang hukum dan bidang penunjang lainnya. Adapun bidang pendidikan meliputi mengajar formal di MI Mathlaul Anwar dan MTS Bina Insani serta mengajar informal yakni mengajar bimbel anak-anak di posko. Bidang ekonomi yakni membuka pola pikir anakanak tentang pentingnya menabung yang sasarannya merupakan anak MI yang bimbel di posko kami, praktik membuat celengan dari botol plastik bekas guna menunjang kreativitas dan juga minat anak-anak agar lebih rajin menabung, dan mengadakan penyuluhan ekonomi bertema "pengelolaan keuangan syariah" yang sasarannya tertuju pada ibu-ibu anggota BKMT. Kemudian di bidang keagamaan kami aktif mengikuti pengajian rutin baik pengajian pemuda yang dilaksanakan di berbagai $\mathrm{rt}$ dan pengajian ibu-ibu, mengadakan TPA sementara di posko, serta mengadakan tabligh akbar. Bidang kesehatan kami ikut aktif dalam kegiatan posyandu, serta mengadakan penyuluhan PHBS di MI Mathlaul anwar dan juga Ponpes Nurul Iman yang tentunya disambut antusias oleh mereka. Penyuluhan hukum yang merupakan program kerja kami pun disambut baik bahkan menciptakan ide untuk mendirikan posdaya desa Barengkok. Adapun bidang penunjang lainnya yaitu kami mengikuti karnaval 17 agustus dari RW 03 sampai kecamatan, bahkan kami ditunjuk sebagai juri oleh desa untuk penilaian kostum dan kreativitas warga desa Barengkok. Kemudian ada juga kegiatan yang kami buat guna meramaikan hari kemerdekaan yakni perlombaan 17 agustus yang bertempat di lapangan depan posko kami. Kami juga mengajukan proposal seribu pohon guna ditanam di desa Barengkok agar membantu pelestarian lingkungan sekitar. 


\section{SARAN}

Kegiatan Kuliah Kerja Nyata ini dilaksanakan untuk membantu masyarakat sekitar dalam pemberian bantuan pemikiran, ide, dan juga tenaga dalam pemecahan masalah setempat. Selain itu kami mengharapkan agar programprogram yang telah dilaksanakan pada saat pelaksanaan KKN terus berjalan dan tidak terhenti saat kegiatan KKN selesai.

Berdasarkan kegiatan $\mathrm{KKN}$ yang telah dilakukan dan dilaksanakan, kami sebagai peserta KKN mempunyai beberapa saran, yakni:

\section{Bagi pemerintah}

Pemerintah seharusnya memberikan penyuluhan tentang dampak buruk jika membuang sampah sembarangan. Faktanya, masih banyak masyarakat sekitar yang masih kurang sadar akan pentingnya kebersihan lingkungan.

Pemerintah juga sebaiknya menyediakan tempat sampah di pemukiman warga juga di pinggir jalan.

\section{Bagi Desa}

Ada baiknya jika pihak desa membuat Tempat Pembuangan Sementara (TPS) serta Tempat Pembuangan Akhir (TPA) agar tidak ada masyarakat yang membuang sampah ke pinggir jalan atau ke sungai lagi.

Kami menyarankan pihak desa agar memberikan motivasi dan saran kepada warga supaya memanfaatkan potensi lokal yang ada menjadi suatu hasil karya baru yang dapat menambah penghasilan warga, mengingat pernah ada hal seperti itu namun kurang didukung oleh pemerintah desa serta masyarakat setempat.

Program penanaman seribu pohon yang kami adakan sebaiknya diawasi dan disosialisasikan kembali pada RT dan RW setempat agar manfaatnya terasa di kemudian hari.

\section{REFERENSI}

\section{Buku Pedoman KKN UIKA}

Green, Youth Strategic to be Leader. Bandung, Gema Pustaka, 1990.

Nugraha, Eva dan Farid Hamzen. Pedoman Pelaksanaan Pengabdian pada Masyarakat oleh Mahasiswa. Jakarta: Pusat Pengabdian kepada Masyarakat, 2013

Peraturan Pemerintah Nomor: 17 Tahun 2010 jo. PP Nomor 66 Tahun 2010 tentang Penyelenggaraan dan Pengelolaan Pendidikan;

Peraturan Pemerintah nomor 37 tahun 2009 tentang Dosen;

Undang-Undang Nomor: 20 Tahun 2003, tentang Sistem Pendidikan Nasional;

UU nomor 14 tahun 2005 tentang Guru dan Dosen;

UU nomor 12 tahun 2012 tentang Perguruan Tinggi; 